\title{
Editor's Message Hydrogeology Journal manuscript processing goes online
}

\author{
Clifford I. Voss, Executive Editor
}

\section{Announcement of New Online System}

Beginning in mid-August 2002, all processing of Hydrogeology Journal (HJ) manuscripts, from submittal to acceptance for publication, is exclusively electronic and online. The author's initial submittal of a manuscript is online (rather than via mailed paper copy). The Editors, Associate Editor, and reviewers all retrieve the manuscript online, the author receives the publication decision and review comments online and submits a revised manuscript online, and the final accepted manuscript is forwarded to the publisher online. Everyone has access to the same online system. $H J$ 's publisher had already provided two online systems for some time - online proof checking and online publication of each manuscript prior to paper publication. The new steps announced here make processing of an $H J$ manuscript, from submittal to publication, completely electronic. In an additional reorganization step, all manuscript tracking is now centralized through the newly established ' $H J$ Editorial Office' located near the International Association of Hydrogeologists (IAH) office in the UK (rather than through the Executive Editor's office in the USA).

These new arrangements should provide several advantages. Mailing and courier costs are reduced for authors and $H J$ staff, because most transactions now occur online. Authors need not make and send multiple copies of their manuscripts, but can already prepare their initial manuscript in the exact final electronic format required for publication. The length of time between manuscript submittal and publication decision will be shorter because not only will manuscript transactions be transported nearly instantaneously, but also all transactions will be carefully tracked by the new $H J$ Editorial Office. This office will prompt all editors and reviewers to keep to promised completion schedules for each review step on each manuscript.

Published online: 24 July 2002

(C) Springer-Verlag 2002

C.I. Voss (

US Geological Survey, 431 National Center, Reston,

Virginia 20192, USA

e-mail: cvoss@usgs.gov

Fax: +1-703-6485274
Paper manuscript submittal will only be accepted by $H J$ when it is impossible for the author to submit online. Whenever possible, authors are expected to use electronic text files and graphics, and to scan non-electronic documents and images creating electronic files that can be submitted online.

The new manuscript tracking system is called Manuscript Central $(M C)$. It was developed by ScholarOne (USA) and was selected by $H J$ 's publisher, SpringerVerlag (Germany). Many of Springer's more than 400 journals will be using $M C$; $H J$ is one of the first to be converted to the new system. The new HJ Editorial Office will be operated by Mrs. Christine Watson, who has already provided some years of support to IAH in the IAH Executive Secretary's office.

\section{How to Access the Online System}

Logging into $M C$ is simple. Online, connect to: http://HydrogeologyJournal.manuscriptcentral.com

The first time you do this, please check for an existing account. Click the "check for existing account" button. If an account exists, you will then receive an automatic e-mail containing your user ID and password. If no account exists, please click "create a new account" and follow the instructions given on the screen and a new user ID and password will be e-mailed to you.

Once you have an account, simply type your user ID and password and $M C$ will open for you. Complete instructions and help regarding online submittal of a manuscript can be found in $M C$. After logging in, authors may submit a new manuscript or track a previously submitted manuscript, and reviewers may open and download a manuscript for review. The access a user has to information in $M C$ depends on the role(s) the user is assigned. Authors may only view some information regarding their own manuscript, reviewers may access the manuscript and review forms, Associate Editors may additionally access reviewer comments and other forms associated with the manuscript, and the Executive Editor may view all information for all manuscripts. 


\section{The Process - From Submittal to Publication}

Each person who has a task associated with a manuscript connects to the $H J-M C$ site and may then access the manuscript online. Persons who must read a manuscript may either do so on the computer monitor, or may download the manuscript (as a pdf file) and print it. Each manuscript is automatically converted to pdf format by $M C$ when submitted by the author; pdf format may be read using Adobe Acrobat Reader, a free utility. Throughout the entire process, from submittal to publication, the $H J$ Editorial Office coordinates all actions among the Executive Editor, Managing Editors, and Associate Editors. $M C$ itself tracks each step of processing a manuscript and automatically notifies the next person that needs to take action when the previous step is completed. User help is available from Springer-Verlag and from the $H J$ Editorial Office.

The new process, described in the following, generally parallels the former process but uses $M C$ online features to coordinate all steps.

\section{- Submittal}

- The corresponding author logs into $M C$ and submits a new manuscript (MS) online, following the instructions found there. If possible, the author should include all text, tables, and figures in a single file so that reviewers will only need to view and download a single file. Text-file formats from most standard word processors and standard graphics formats are acceptable for online submittal.

- Initial review

- The $H J$ Editorial Office checks that the MS is complete. If illustrations have arrived on paper, these are scanned and included online with the MS.

- The Executive Editor conducts an initial review of the MS and, if it is within the scope of subjects that $H J$ publishes, assigns an Associate Editor (AE) to manage technical reviews. AE assignment takes place online within $M C$.

\section{- Technical review}

- The assigned AE reviews the MS and selects two technical reviewers. HJ AEs may decide to conduct one of the technical reviews themselves or they may find two other technical reviewers. Invitations to reviewers and reviewer assignments are done online in $M C$ by the AE.

- Each reviewer connects to $M C$, conducts a careful, comprehensive technical review, and returns a reviewer rating sheet and written comments online within $M C$. If the reviewer also wishes to place some handwritten review comments on a paper copy of the MS, it must be mailed back to the AE, though this is not encouraged.

- The AE considers all reviewer comments and ratings and completes an AE rating sheet and written recommendation online within $M C$.
- Decision process

- The reviewed MS is given to one of the two $H J$ Managing Editors (MEs), who checks the comments of the $\mathrm{AE}$ and reviewers and makes a publication decision. The ME forwards the decision (accept or reject), the reviews, and the comments to the author via e-mail, indicating whether specific revisions are necessary before publication.

- If the MS is accepted for publication, subject to revision, the author must revise it in order have it to published. The author may discuss or question the ME's decision, the reviewer comments, or the revisions required for publication, by sending an e-mail to the ME.

\section{- Revision process}

- The author submits a revised MS online in the same manner as for the initial submittal.

- The ME reviews the revised MS and makes another publication decision. Either further revision is required or the MS is accepted for publication.

- Submittal of final MS and checking proofs

- For final submittal, following acceptance, the author is requested to submit separate files online in $M C$ for the text and for each figure. This is required by the publisher to allow processing of the various file types. The publisher retrieves the final MS from $M C$.

- Within a few weeks following final submittal, proofs (in HTML and pdf formats) are provided online by the publisher, Springer-Verlag, for checking by the author and ME. This is the last possible check prior to publication.

\section{- Publication of MS}

- Within 2 weeks of completing the check of the proofs, the manuscript is officially published online on Springer's LINK site for HJ (http:// link.springer.de/journals/hydrogeo/) with a unique DOI reference number (Digital Object Identifier registered with the International DOI Foundation). This online publication is citable by journal title and DOI. All articles published in $H J$ may be found on the LINK site.

- The manuscript is subsequently also published in the next available paper issue of $H J$.

\section{Transition Between Old and New Systems}

During the initial transition period, manuscripts previously under review will not exist within the new online $M C$ system. For such manuscripts, when authors are asked to make revisions, they will do so online in $M C$ and will enter the new system in this manner. Authors who have submitted new manuscripts in the past few months will be asked by $H J$ to again submit their manuscript online for continued processing. These authors will receive an e-mail with instructions. 